\title{
TAK1/AP-1-Targeted Anti-Inflammatory Effects of Barringtonia augusta Methanol Extract
}

\author{
Anh Thu Ha ${ }^{1}$, Mi-Yeon Kim ${ }^{2, *}$ and Jae Youl Cho ${ }^{1, *(D)}$ \\ 1 Department of Integrative Biotechnology, and Biomedical Institute for Convergence at SKKU (BICS), \\ Sungkyunkwan University, Suwon 16419, Korea; anhthu95.vn@gmail.com \\ 2 School of Systems Biomedical Science, Soongsil University, Seoul 06978, Korea \\ * Correspondence: kimmy@ssu.ac.kr (M.-Y.K.); jaecho@skku.edu (J.Y.C.); Tel.: +82-2-820-0458 (M.-Y.K.); \\ $+82-31-290-7868$ (J.Y.C.)
}

check for

updates

Citation: Ha, A.T.; Kim, M.-Y.; Cho, J.Y. TAK1/AP-1-Targeted Anti-Inflammatory Effects of Barringtonia augusta Methanol Extract. Molecules 2021, 26, 3053. https:// doi.org/10.3390/molecules26103053

Academic Editor: Edmund M.K. Lui

Received: 19 April 2021

Accepted: 18 May 2021

Published: 20 May 2021

Publisher's Note: MDPI stays neutral with regard to jurisdictional claims in published maps and institutional affiliations.

Copyright: (c) 2021 by the authors. Licensee MDPI, Basel, Switzerland. This article is an open access article distributed under the terms and conditions of the Creative Commons Attribution (CC BY) license (https:/ / creativecommons.org/licenses/by/ $4.0 /)$.

\begin{abstract}
Barringtonia augusta methanol extract (Ba-ME) is a folk medicine found in the wetlands of Thailand that acts through an anti-inflammatory mechanism that is not understood fully. Here, we examine how the methanol extract of Barringtonia augusta (B. augusta) can suppress the activator protein 1 (AP-1) signaling pathway and study the activities of Ba-ME in the lipopolysaccharide (LPS)treated RAW264.7 macrophage cell line and an LPS-induced peritonitis mouse model. Non-toxic concentrations of Ba-ME downregulated the mRNA expression of cytokines, such as cyclooxygenase and chemokine ligand 12, in LPS-stimulated RAW264.7 cells. Transfection experiments with the AP1-Luc construct, HEK293T cells, and luciferase assays were used to assess whether Ba-ME suppressed the AP-1 functional activation. A Western blot assay confirmed that C-Jun N-terminal kinase is a direct pharmacological target of Ba-ME action. The anti-inflammatory effect of Ba-ME, which functions by $\beta$-activated kinase 1 (TAK1) inhibition, was confirmed by using an overexpression strategy and a cellular thermal shift assay. In vivo experiments in a mouse model of LPS-induced peritonitis showed the anti-inflammatory effect of Ba-ME on LPS-stimulated macrophages and acute inflammatory mouse models. We conclude that Ba-ME is a promising anti-inflammatory drug targeting TAK1 in the AP-1 pathway.
\end{abstract}

Keywords: Barringtonia augusta; anti-inflammatory effect; TAK1

\section{Introduction}

Inflammation, which plays an important role in protecting the body from harmful external influences, is associated with pain, swelling, heat, redness, and various functional impairments, and presents acute and chronic responses [1-3]. Without effective treatment, acute inflammation can become chronic. Hyperactive and prolonged inflammatory responses are considered important factors in various diseases, such as autoimmune disorder, cancer, diabetes, arthritis, and several vascular diseases [4,5]. Innate and adaptive immunity are the two parts of the immune system. The innate immune mechanism, which controls the activities of inflammatory response cells, comprises macrophages, neutrophils, and dendritic cells [6].

Toll-like receptors (TLRs) are proteins that have vital roles in the innate immune system. [6]. Lipopolysaccharide (LPS) is a major part of the TLR4 ligand [7]. Mitogenactivated protein kinase (MAPK) signaling was activated in the course of LPS-induced inflammation, because LPS binds to TLR4 and stimulates the recruitment of both TRIF adaptor proteins and cytoplasmic MyD88 [8]. MAPK families include extracellular signalregulated kinase (ERK), c-Jun N-terminal kinase (JNK), and p38 kinase [9]. When TAK1 is activated, a sequential signaling cascade composed of mitogen-activated protein kinase kinases (MAPKKs) and kinase IKK is activated [10]. MAPKKs or IKK phosphorylate MAPK (JNK, ERK, and p38 or inhibitor of $\kappa \mathrm{B} \alpha \mathrm{I} \kappa \mathrm{B} \alpha$ ) to activate activator protein 1 (AP-1) [11]. Activation of AP-1 increases when the MAPK signaling pathway is activated. The AP-1 
signaling pathway consists of ATF, c-Fos, c-Jun, and JDP families [12,13]. Because many inflammatory diseases in humans occur with the activation of AP-1 [14], targeting the MAPK/AP-1 pathway is a promising and attractive therapeutic anti-inflammatory method.

The onset and intensification of inflammation in the body occasionally activate macrophages and release more cytokines, such as tumor necrosis factor-alpha (TNF- $\alpha$ ), interleukin 6 (IL-6), IL-1beta, IL-12, and interferons [15]. Inflammatory genes include cyclooxygenase-2 (COX-2) and inducible nitric oxide synthase (iNOS) [16]. Cytokines and inflammatory genes are upregulated by activation of AP- 1 transcription factors and nuclear factor kappa B (NF-kB). Therefore, decreasing inflammation is an important therapeutic goal and possibly prevents infection in the human body.

Traditional medicine and natural extracts offer benefits to healthcare and the treatment of various diseases [17]. Nowadays, studies have been developing with original plant extracts that are rich in antioxidants of a phenolic nature to study anti-inflammatory, antimicrobial, anticholinesterase effects, etc. Traditional medicines-more specifically, herbal extracts-have proven their effectiveness in the treatment of various diseases and are now gaining more attention among the scientific community for their potential in the development of medicine for treating urgent and contemporary diseases of the modern era. Most notably, Sytar et al. demonstrated the possible role of plant-derived natural antiviral compounds for the development of plant-based drugs against the representative coronaviruses group - specifically, COVID-19, which has caused a global pandemic that is currently ongoing [18]. Thymus species, which are culinary herbs and flavoring agents in Europe, North Africa, and Asia, have also proved to be promising therapeutic agents for neurodegenerative disorders (e.g., Alzheimer's disease, which is currently ranked as the sixth leading cause of death in the United States) [19]. The anti-oxidative and anti-inflammatory effects of the variety of plants collected from 14 original research papers have been comprehensively reviewed and summarized by Allegra, providing an overview of the original plant extract's antioxidants, which are phenolic in nature, for investigation of its anti-inflammatory, antimicrobial, anticholinesterase effects, etc. [20]. These previous works inspired us to attempt to utilize traditional medicine and natural extracts for anti-inflammatory applications. Interestingly, Barringtonia racemosa (a traditional plant in Malaysian villages) has been employed for human breast cancer treatment, drug discovery, and development [21]. In the same manner, in this research, we explored Barringtonia augusta, which is found in the wetlands of Thailand. Extracts of B. augusta exhibit antioxidant properties [22], although the molecular mechanisms by which they inhibit inflammatory responses through the AP-1 signaling pathway are not understood. In this study, we explored the anti-inflammatory effect of $B$. augusta methanol extract (Ba-ME). We investigated the roles of this compound in the regulation of the AP-1 signaling pathway in an LPS-treated macrophage RAW264.7 cell line and an LPS-induced peritonitis mouse model.

\section{Results}

\subsection{Effect of Ba-ME on Cell Viability and Expression Levels of Inflammatory Genes in LPS-Treated Cells}

We inspected the cell cytotoxicity of Ba-ME (25-50 $\mu \mathrm{g} / \mathrm{mL})$ in RAW264.7 and HEK293T cells by MTT assay (Figure 1a,b). The viability of RAW264.7 and HEK293T cells was not affected notably by Ba-ME treatment compared with untreated cells.

We employed a reverse transcription PCR (RT-PCR) assay to examine the transcriptional level of pro-inflammatory genes. We measured the expression of the proinflammatory cytokines, such as chemokine (C-C motif) ligand 12 (CCL12), C-X-C motif chemokine ligand 3 (CXCL3), Chemokine (C-X-C motif) ligand 9 (CXCL9), Cyclooxygenase2 (COX-2), and glyceraldehyde 3-phosphate dehydrogenase (GAPDH). CCL12 and COX-2 expression were decreased by Ba-ME treatment in a dose-dependent manner (Figure 1c). Because the mRNA expression levels of these cytokines are interconnected through the AP-1 pathway, we confirmed that Ba-ME attenuated the AP-1 pathway. 


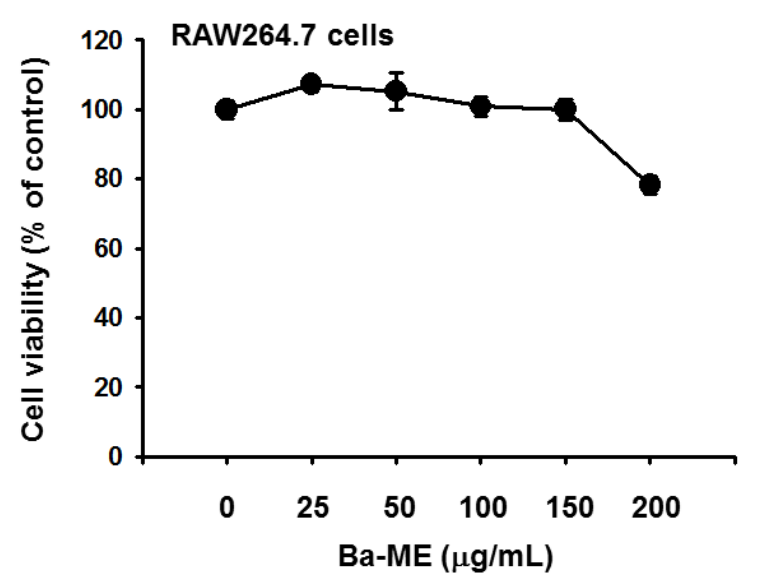

(a)

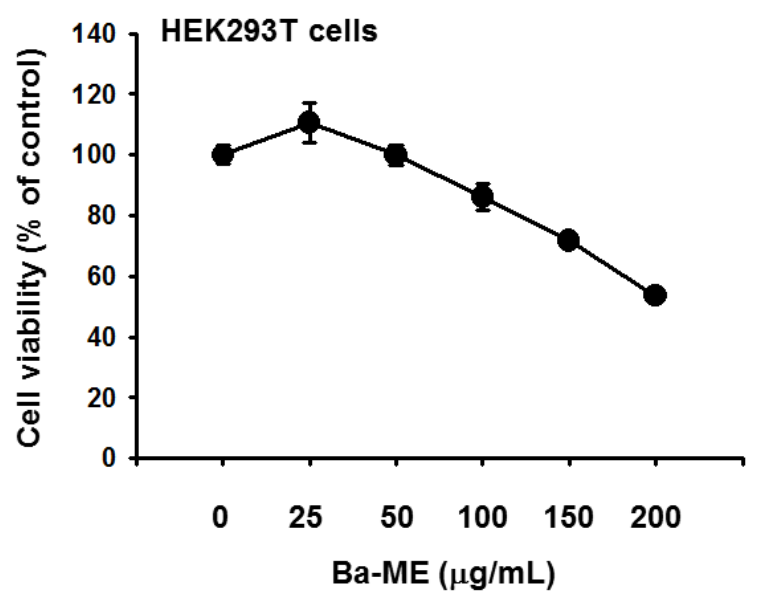

(b)
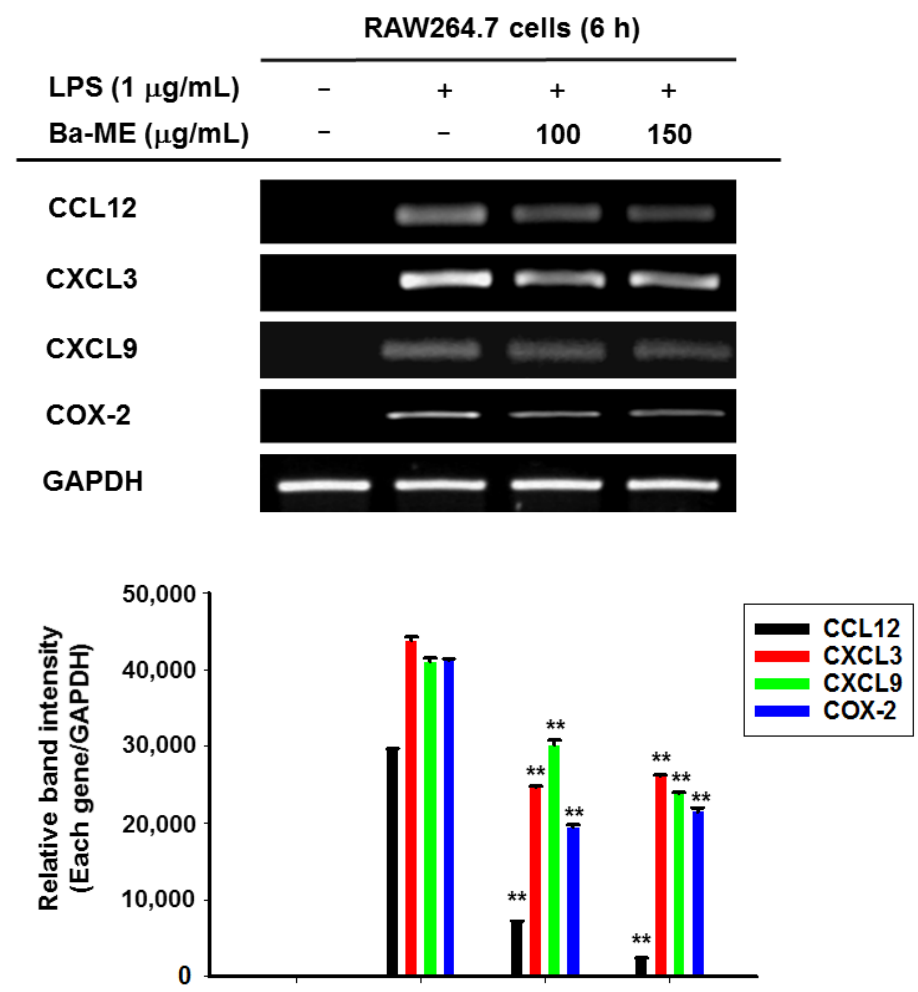

(c)

Figure 1. Effects of Ba-ME on cell viability and inflammatory gene expression in LPS-treated cells. (a) Treated RAW264.7 cells with Ba-ME with the indicated concentrations for $24 \mathrm{~h}$. Used MTT assay to measure the cell viability. The values are presented as mean \pm SD of 3 replicates. (b) HEK293T cells were treated with different Ba-ME concentrations for $24 \mathrm{~h}$, and the MTT assay was performed to determine cell viability. The values are presented as mean \pm SD of 3 replicates. (c) Employing RT-PCR to detect the mRNA expression levels of CCL12, CXCL3, CXCL9, COX-2, and GAPDH in LPS-stimulated RAW264.7 cells treated with Ba-ME $(0-50 \mu \mathrm{g} / \mathrm{mL})$. Band intensity (the bottom panel of $(\mathbf{c}))$ was measured and quantified using ImageJ. ** $p<0.01$ compared with control cells.

\subsection{Effect of Ba-ME on Transcriptional Activation of AP-1}

Due to the regulatory role of the AP-1 transcription factor in inflammatory gene expression, we decided to inspect the suppressive effect of Ba-ME on such activation. In order to determine whether Ba-ME suppressed the activation of AP-1, a transfection experiment with the AP-1-Luc construction and HEK293T cells was conducted. The result showed that AP-1-mediated luciferase activity was intensified by co-transfection with TRIF and MyD88. In contrast, Ba-ME treatment inhibited this upregulation significantly $(p<0.01)$ with dose dependence (Figure 2). These results indicate that AP-1 activation is a vital pharmacological target of Ba-ME.

\subsection{Regulatory Mechanism of Ba-ME in AP-1 Pathways}

Whether Ba-ME can suppress the activation and translocation of AP-1 was our next investigation in this study. Figure 3a shows the increase in nuclear levels of the AP-1, c-Fos, and c-Jun subunits due to time-dependent $(5,15,30$, and $60 \mathrm{~min})$ inhibition by 
Ba-ME. Similar time-dependent (5 min) inhibitory c-Fos and c-Jun expression patterns were confirmed from RAW264.7 cells by whole lysate extraction.

It is an important and non-trivial task to establish which intracellular molecules are targeted by Ba-ME in the AP-1 signaling pathway. We measured the levels of phosphorylated MAPKs (p-38, ERK, and JNK). We noticed that LPS obviously raised the phosphorylation of ERK, JNK, and p-38. In contrast, the phosphorylation of JNK was suppressed by Ba-ME strongly and time-dependently $(5,15,30,60 \mathrm{~min})$, but that of p-38 and ERK (Figure 3b,c) in RAW264.7 cells was not after the treatment of Ba-ME. As phosphorylation of MAPKs is crucial in regulating the LPS-induced inflammatory mediators, our results confirmed that Ba-ME blocks the AP-1 pathway through the expression level of JNK.

We analyzed the phosphorylated forms of AP-1-related proteins to identify the targeted protein of Ba-ME in inhibiting the AP-1 pathway. As shown in Figure 4a, phosphorylated TAK1 was detected by LPS induction for 2, 3, and $5 \mathrm{~min}$. TAK1 is the most upstream protein in the AP-1 pathway; it orders AP- 1 signaling to progress, and its activation is required to activate macrophages. Using a Western blot assay, we observed that TAK1, the phosphorylated forms of AP-1 pathway-related proteins [11], were decreased by Ba-ME at 2,3 , and $5 \mathrm{~min}$. This result proved that Ba-ME specifically targets TAK1. Moreover, the inhibition of TAK1 kinase alleviates the activation of downstream proteins.

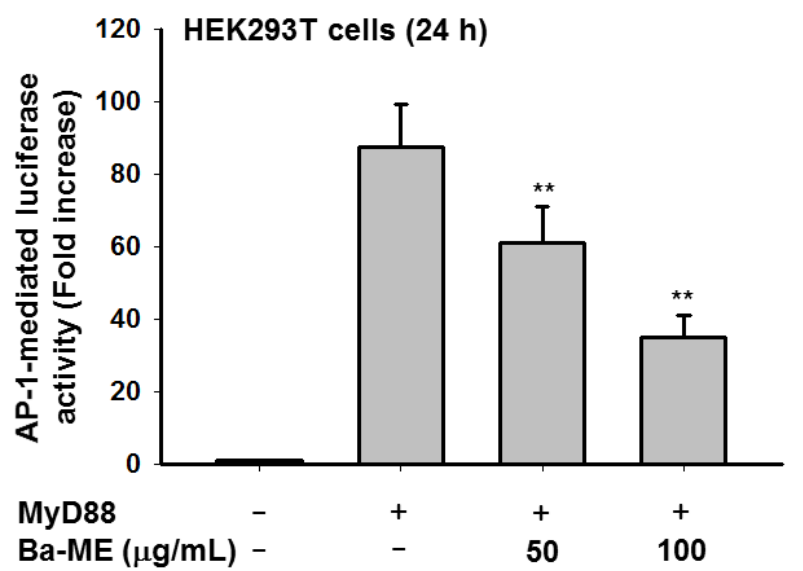

(a)

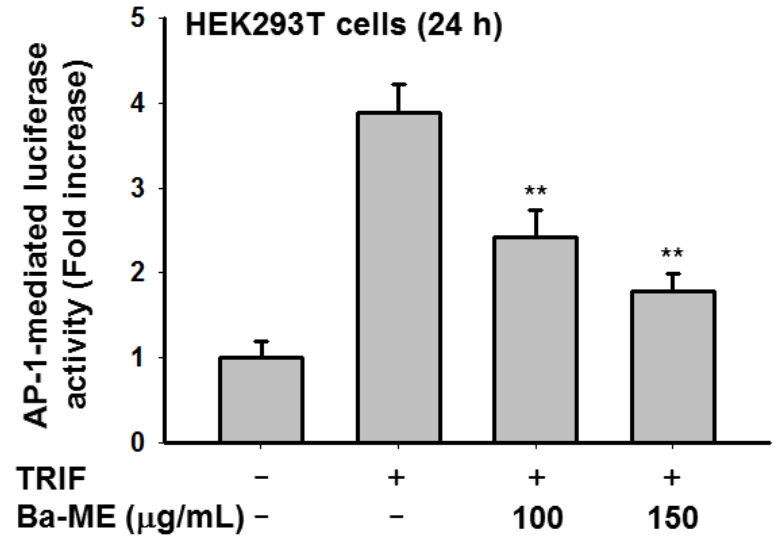

(b)

Figure 2. Effect of Ba-ME on activation of AP-1 pathways. (a,b) HEK293T cells were transfected with AP-1-Luc and $\beta$-gal constructs with Tag2-MyD88 (a) or CFP-TRIF (b). HEK293T cells were additionally treated with Ba-ME $(0-100 \mu \mathrm{g} / \mathrm{mL})$ for $24 \mathrm{~h}$. AP-1-driven luciferase activity was measured by a luminometer. ${ }^{* *} p<0.01$ compared with control cells. The values are presented as mean $\pm \mathrm{SD}$ of 3 replicates. 


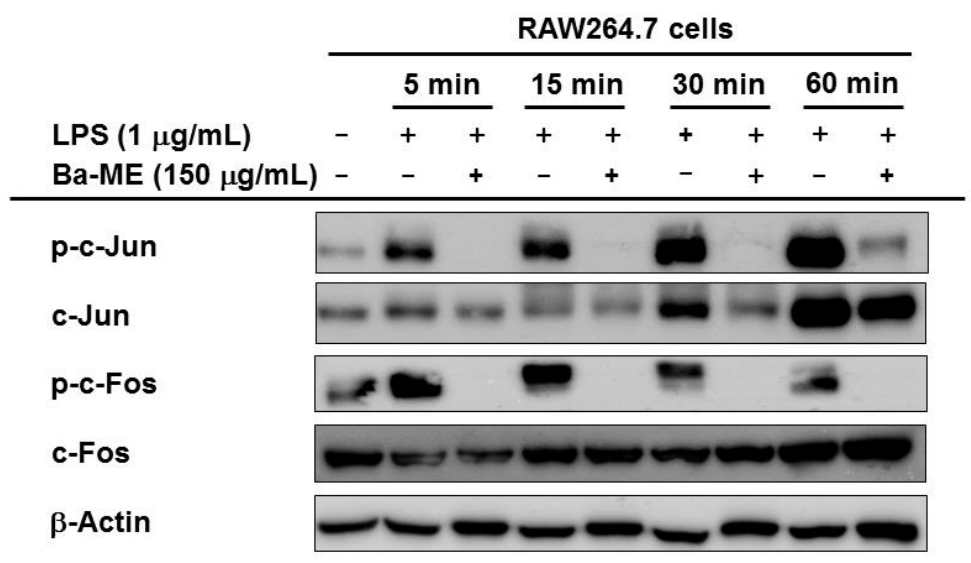

(a)

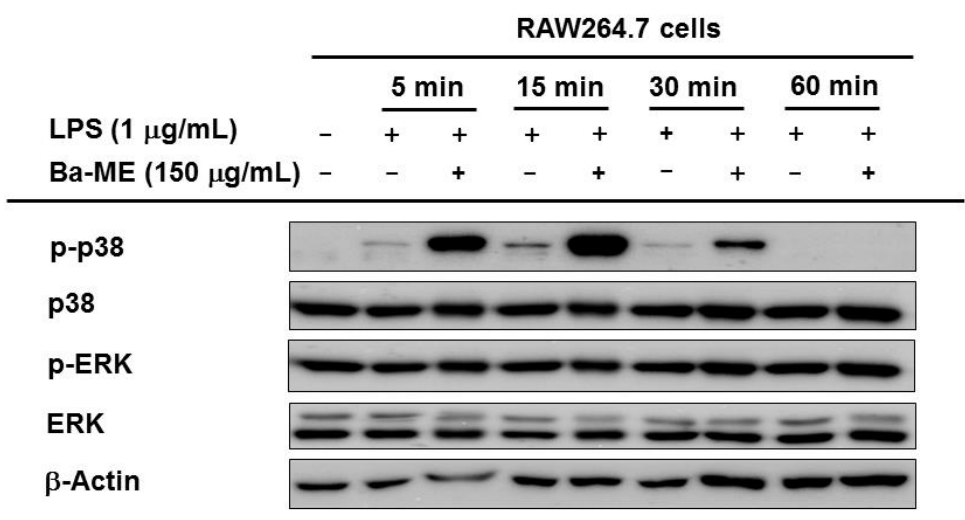

(b)

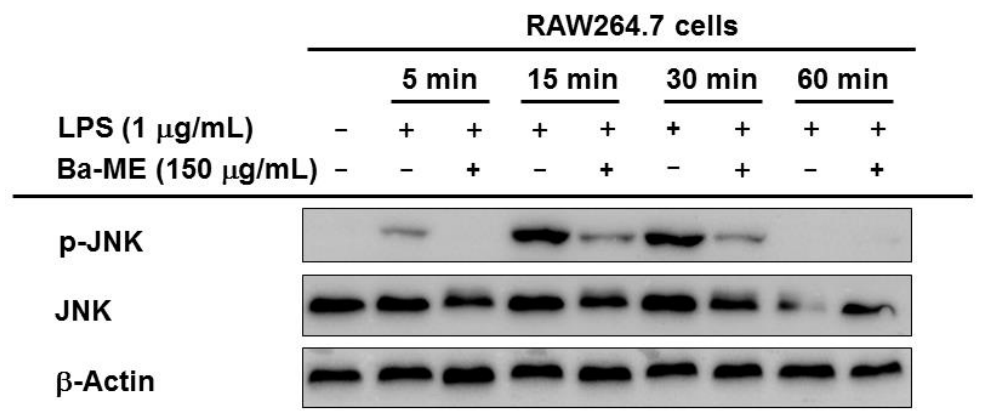

(c)

Figure 3. Effect of Ba-ME on intracellular signaling molecules' activation in the AP-1 pathway. (a-c) Treated RAW264.7 cells with LPS $(1 \mu \mathrm{g} / \mathrm{mL})$ for 5, 15, 30, $60 \mathrm{~min}$ in the absence or presence of Ba-ME $(150 \mu \mathrm{g} / \mathrm{mL})$. A Western blot analysis determined the levels of phosphorylated forms and total forms of c-Jun and c-Fos (a). Using an immunoblot analysis of cell lysates to determine the phosphoprotein levels of p-38, ERK, JNK, and $\beta$-actin $(\mathbf{b}, \mathbf{c})$. 


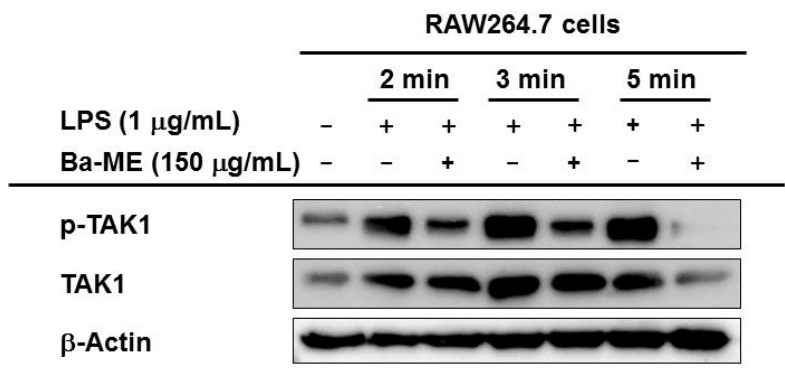

(a)

\begin{tabular}{|c|c|}
\hline \multirow[b]{2}{*}{ pPRK6-HA-TAK1 } & HEK293T cells \\
\hline & + \\
\hline Ba-ME $(\mu \mathrm{g} / \mathrm{mL})$ & 150 \\
\hline p-TAK1 & $2=$ \\
\hline TAK1 & $3=0$ \\
\hline HA & \\
\hline$\beta$-actin & \\
\hline
\end{tabular}

(b)

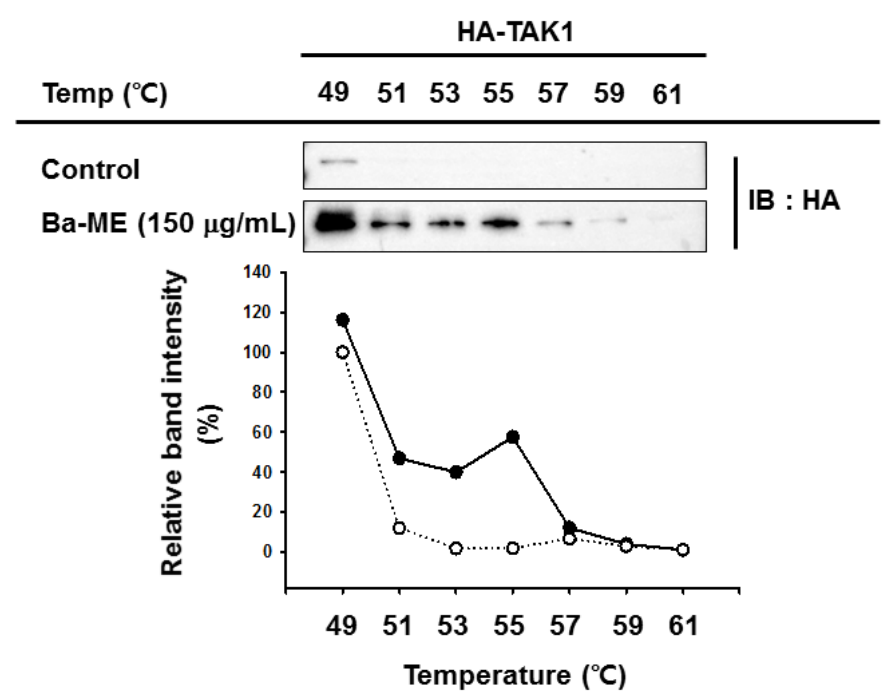

(c)

Figure 4. (a) RAW264.7 cells were incubated with Ba-ME in the absence or presence of LPS $(1 \mu \mathrm{g} / \mathrm{mL})$ for the designated times. After whole-cell lysates, employing immunoblotting to identify levels of total and phosphoforms of upstream TAK1 signaling enzymes. (b) After $24 \mathrm{~h}$ transfected pPRK6HA-TAK1 constructs with HEK293T cells, treatmentt with Ba-ME was advisable, using a Western blot analysis to determine the levels of phosphorylated and total forms of TAK1-HA. (c) After overexpressing TAK1 in HEK293T cells, a CETSA was performed with Ba-ME $(150 \mu \mathrm{g} / \mathrm{mL})$, and dimethyl sulfoxide was used as a control. A Western blot analysis was conducted to examine the stabilization of Ba-ME on TAK1. Solid circles are Ba-ME group and hollow circles are control group. 


\subsection{Anti-Inflammatory Effects of Ba-ME by Targeting TAK1}

The whole cell lysate immunoblotting, which used HEK293T cells to overexpress TAK1, was conducted to examine Ba-ME's capability in inhibiting autophosphorylation of target enzymes. We overexpressed the plasmids expressing pPRK6-HA-TAK1 in HEK293T cells after $24 \mathrm{~h}$ and exposed the cell that was treated to Ba-ME $(150 \mu \mathrm{g} / \mathrm{mL})$ for another $24 \mathrm{~h}$. The p-TAK1 level was reduced by the Ba-ME treatment (Figure $4 \mathrm{~b}$ ).

To assess the interaction of Ba-ME with TAK1 in intact cells, we performed a cellular thermal shift assay (CETSA) at $49^{\circ} \mathrm{C}, 51^{\circ} \mathrm{C}, 53^{\circ} \mathrm{C}, 55^{\circ} \mathrm{C}, 57^{\circ} \mathrm{C}, 59^{\circ} \mathrm{C}$, and $61^{\circ} \mathrm{C}$. Figure $4 \mathrm{C}$ shows that Ba-ME treatment shifted the thermal stability of the target protein TAK1.

\subsection{Ba-ME Alleviates Clinical Signs of LPS-Induced Peritonitis in a Mouse Model}

An LPS-induced peritonitis mouse model was established to examine the anti-inflammatory effect of Ba-ME in vivo. Ba-ME $(100 \mathrm{mg} / \mathrm{kg}$ ) clearly decreased nitric oxide (NO) production (Figure 5a). Next, the mRNA expression levels and protein levels of AP-1 pathwayrelated factors were examined. Figure $5 b$ indicates that the mRNA levels of COX- 2 and CCL12 decreased. These observations indicate that Ba-ME has the capability to inhibit the progression of the AP-1 pathway, by proving its anti-inflammatory effect in vitro and in vivo.

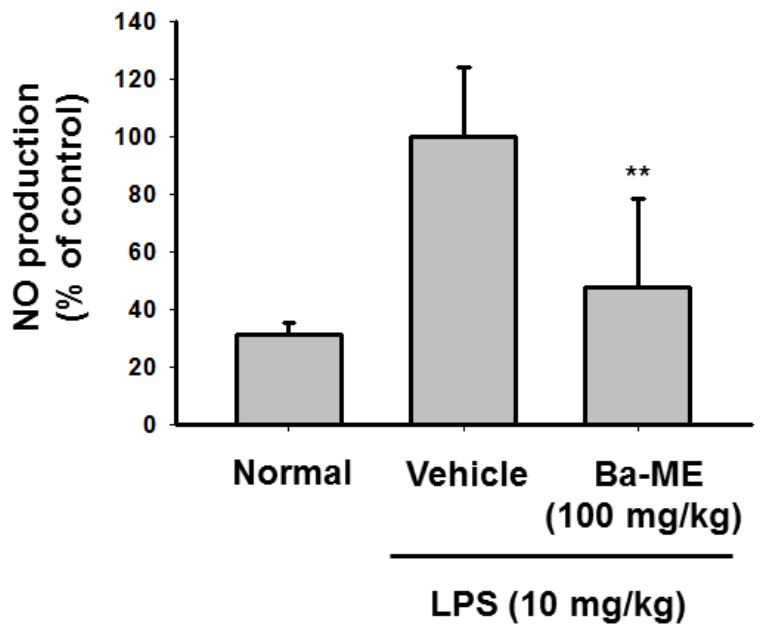

(a)

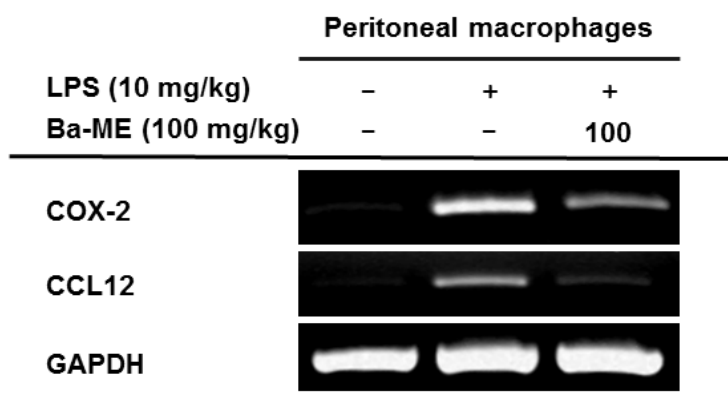

(b)

Figure 5. Effect of Ba-ME on regulating inflammation in an LPS-induced peritonitis mouse model. (a) Peritoneal macrophage inflammatory lesions were examined with an NO assay. (b) The mRNA expression levels of COX-2, CCL12, and GAPDH in peritoneal macrophages treated with Ba-ME $(100 \mathrm{mg} / \mathrm{kg})$ were determined using semiquantitative RT-PCR. ${ }^{* *} p<0.01$ compared with control cells. The values (a) are presented as mean \pm SD of 5 replicates.

\section{Discussion}

Barringtonia augusta has long been used as a folk medicine and is understood to act as an antioxidant [22]. However, a molecular mechanism that explains how Ba-ME inhibits inflammatory responses to the AP-1 signaling pathway has yet to be elucidated. We focused on how Ba-ME exerts its anti-inflammation function in vitro using LPS-stimulated RAW267.4 cells and an in vivo LPS-induced peritonitis mouse model.

The viability of HEK293T cells and RAW264.7 was examined to determine how Ba-ME produces anti-inflammatory effects without cytotoxicity (Figure 1) using an MTT assay [23]. LPS-stimulated TLR4 signaling modulates the COX-2 and pro-inflammatory cytokines by activating AP-1 pathways in macrophages [24,25]. Our goal was to determine whether Ba-ME mediates the downregulation of COX-2 and whether inflammatory cytokines are mediated in LPS-stimulated macrophages by suppressing AP-1 signaling. 
Previously, O'Neill et al. demonstrated a method for identifying the essential components of TLR signaling that employed the transfection with a luciferase reporter gene construction and adaptor molecules in HEK cells [26]. As demonstrated in our studies $[27,28]$, this method was obviously found to be reliable in investigating the functional activation of transcription factors. Following this approach, we transfected cells containing AP-1-Luc with adaptor molecules (TRIF and MyD88) to examine how Ba-ME suppresses AP-1 transcription activity (Figure 2). The AP-1-mediated luciferase activity was accelerated up to a factor of 6.5 by TRIF and MyD88 co-transfection while Ba-ME significantly and dose-dependently blocked this activity. Altogether, AP-1 activation is a pharmacologic target of the extract.

We exposed the RAW264.7 cells to LPS and measured the phosphorylated and total levels of c-Jun and c-Fos to comprehensively examine the effect on the AP-1 signaling pathway of Ba-ME. Figure 3a shows that Ba-ME can decrease levels of phosphorylated c-Jun and c-Fos in RAW264.7 cells under LPS stimulation conditions. It has been stated that MAPKs are able to control AP-1 activation, thus playing an important role in regulating LPS-induced inflammation $[28,29]$. In the same manner, our results suggest that Ba-ME specifically targets an upstream MAPK. We further analyzed the inhibitory effect of Ba-ME on MAPKs and their upstream signaling enzymes. We had to examine the effects of Ba-ME on the activity levels of the phosphorylated and total forms of p38, JNK, and ERK because there are many kinds of MAPKs (such as p38, JNK, and ERK) that activate AP-1 signaling pathways. Although the activity of p38 and ERK was not inhibited, Ba-ME inhibited the activity of kinase JNK at 5, 10, 15, 30, and $60 \mathrm{~min}$, as shown in Figure 3c. The results indicate that Ba-ME targets were upstream signaling molecules in the AP-1 signaling pathways of anti-inflammatory activity. Brief experiments performed at 2, 3, and 5 min (Figure 4a) revealed that LPS enhanced the TAK1 phosphorylation, which takes place upstream of JNK. These results confirmed the MAPK inhibitory activity of Ba-ME.

To evaluate whether Ba-ME targets upstream AP-1 signaling molecules, we employed TAK1-overexpressing HEK293T cells. As shown in Figure 4b, Ba-ME suppressed the phosphorylation of TAK1. We examined whether TAK1 is the target of Ba-ME using CETSA experiments to identify interactions between Ba-ME and TAK1. The results confirmed that Ba-ME interacts with TAK1.

The LPS-induced peritonitis mouse model was employed for exploring the antiinflammatory ability of Ba-ME in vivo. As shown in Figure 5, the Ba-ME treatment $(100 \mathrm{mg} / \mathrm{kg})$ improved LPS-induced peritonitis. The NO production assay (Figure 5a) helped us to confirm the suppressive effect of Ba-ME. Moreover, Ba-ME reduced inflammatory lesions, pro-inflammatory cytokines, and activation of AP-1 pathway-related proteins in the peritonitis model. These reports agree with the previously demonstrated effects of Ba-ME on mRNA production and active forms of AP-1 signaling molecules. Ba-ME was strongly peritonitis-protective in the mouse model of LPS-induced peritonitis. These results indicate that Ba-ME is a potential candidate for an anti-inflammatory medicine component.

\section{Materials and Methods}

\subsection{Materials}

Barringtonia augusta methanol extract (Lecythidaceae) was extracted from the leaf and stem of the plant from Vietnam. The phytochemical details of Ba-ME, including HPLC profile, are presented in the Supplementary Information. RAW264.7 and HEK293T cells were purchased from American Type Culture Collection (Rockville, MD, USA). Roswell Park Memorial Institute 1640 medium (RPMI 1640), Dulbecco's modified Eagle's medium, fetal bovine serum (FBS), and phosphate-buffered saline (PBS) were purchased from Capricorn Scientific GmbH (Ebsdorfergrund, Germany). TRIzol reagent was purchased from MRCgene (Cincinnati, OH, USA). MTT, sodium dodecyl sulfate, dimethyl sulfoxide (DMSO), polyethylenimine (PEI), and LPS (E. coli 0111: B4) were purchased from Sigma-Aldrich Co. (St. Louis, MO, USA). Penicillin-streptomycin and trypsin were purchased from HyClone (Logan, UT, USA). PCR premix and primers specific for COX-2, CCL12, CXCL3, CXCL9, 
and GAPDH were synthesized by Bioneer Inc. Antibodies specific for the phosphorylated and total forms of c-Fos, c-Jun, p38, ERK, JNK, TAK1, and $\beta$-actin were acquired from Cell Signaling Technology (Beverly, MA, USA).

\subsection{Cell Cultures}

A murine macrophage cell line (RAW264.7) was cultivated in RPMI 1640 medium supplemented with $10 \%$ heat-inactivated FBS and antibiotics (penicillin and streptomycin) at $37{ }^{\circ} \mathrm{C}$ in $5 \% \mathrm{CO}_{2}$. Human embryonic kidney cell line (HEK293T) was cultured in cultured in DMEM medium with 5\% heat-inactivated FBS and antibiotics (penicillin and streptomycin) at $37^{\circ} \mathrm{C}$ in $5 \% \mathrm{CO}_{2}$.

\subsection{Mice}

Male C57BL/ 6 Institute of Cancer Research mice (6 to 8 weeks old, 17 to $21 \mathrm{~g}$ ) were obtained from Deahan Biolink (Chungbuk, Korea) and treated orally with Ba-ME (100 mg/kg) or ranitidine $(40 \mathrm{mg} / \mathrm{kg})$ twice per day for 3 days. Water and pellet chow were available ad libitum (Samyang, Daejeon, Korea). Studies (the permit number for experimentation on mice: SKKUIACUC2020-06-30-1) were performed following instructions established by the Sungkyunkwan University Institutional Animal Care and Use Committee.

\subsection{Cell Viability Tests}

The cytotoxicity of Ba-ME $\left(5 \times 10^{5}\right.$ cells $\left./ \mathrm{mL}\right)$ was assessed for $24 \mathrm{~h}$, and HEK293T cells $\left(2 \times 10^{5} / \mathrm{mL}\right)$ were measured by MTT assays [6]. The cytotoxic effect of Ba-ME $(25-50 \mu \mathrm{g} / \mathrm{mL})$ was evaluated by a conventional MTT assay. The final concentration of MTT solution was $500 \mu \mathrm{g} / \mathrm{mL}$. Cells were treated with Ba-ME for $24 \mathrm{~h} ; 10 \mu \mathrm{L}$ of MTT solution was added to cells $3 \mathrm{~h}$ prior to the end of the culture period. The addition of $15 \%$ sodium dodecyl sulfate to each well to dissolve the formazan stopped the assay. Absorbance at $570 \mathrm{~nm}$ was measured using a Synergy HT multi-mode microplate reader (BioTek Instruments, Inc., Winooski, VT, USA).

\section{5. mRNA Analysis by Quantitative Reverse Transcription Polymerase Chain Reaction}

RAW264.7 cells $\left(1 \times 10^{6}\right.$ cells $\left./ \mathrm{mL}\right)$ were treated with Ba-ME $(100-150 \mu \mathrm{g} / \mathrm{mL})$, and induction was executed with LPS $(1 \mu \mathrm{g} / \mathrm{mL})$ after $30 \mathrm{~min}$. After $6 \mathrm{~h}$ of induction, RNA was extracted by a TRI reagent according to the manufacturer's instructions and stored at $-80^{\circ} \mathrm{C}$. A $1 \mu \mathrm{g}$ sample of total RNA was used in a cDNA synthesis kit (Thermo Fisher Scientific, Waltham, MA, USA) following the manufacturer's instructions [30,31]. The used primer sequences are listed in Table 1.

Table 1. Primer sequences for analysis of mRNA prepared from RAW264.7 cells used in RT-PCR.

\begin{tabular}{ccc}
\hline Name & Direction & Sequence $\mathbf{( 5}^{\prime}$ to $\left.\mathbf{3}^{\prime}\right)$ \\
\hline \multirow{2}{*}{ COX-2 } & Forward & CACTACATCCTGACCCACTT \\
\cline { 2 - 3 } & Reverse & ATGCTCCTGCTTGAGTATGT \\
\hline \multirow{2}{*}{ CCL12 } & Forward & GCCTCCTGCTCATAGCTACC \\
\cline { 2 - 3 } CXCL3 & Reverse & CTTCCGGACGTGAATCTTCT \\
\cline { 2 - 3 } & Forward & CCAACGGTGTCTGGATGTGT \\
\hline \multirow{2}{*}{ CXCL9 } & Reverse & TGGCCAGCCAAGGAATACTG \\
\cline { 2 - 3 } & Forward & ACAGGTTGACTGATTGGCA \\
\hline \multirow{2}{*}{ GAPDH } & Reverse & GCTSSSGGATTTGGCAGCTC \\
\hline & Forward & ACCACAGTGGATGCCATCAC \\
\hline
\end{tabular}




\subsection{Plasmid Transfection and Luciferase Reporter Gene Activity Assays}

HEK293T cells $\left(2.5 \times 10^{5} / \mathrm{mL}\right)$ were seeded in 24-well plates. The cells were transfected with plasmids encoding a luciferase gene (AP-1-Luc) with AP-1 promoter sites. MyD88 or TRIF genes were then co-transfected to further activate the luciferase genes. Transfections were performed using the polyethylenimine (PEI) method. After $24 \mathrm{~h}$, we treated the transfected cells with Ba-ME $(0-150 \mu \mathrm{g} / \mathrm{mL})$. The harvested cells were lysed by freezing at $-70{ }^{\circ} \mathrm{C}$ for at least $3 \mathrm{~h}$. A luminometer was used to measure luciferase reporter activity [32].

\subsection{Western Blot Analysis}

RAW264.7 cells $\left(1 \times 10^{6} / \mathrm{mL}\right)$ were pretreated with Ba-ME $(150 \mu \mathrm{g} / \mathrm{mL})$ for $30 \mathrm{~min}$, after which LPS induction $(1 \mu \mathrm{g} / \mathrm{mL})$ was processed for indicated times $(2,3,5,15,30$, and $60 \mathrm{~min})$. HEK293T cells were overexpressed with TAK1 for $48 \mathrm{~h}$ and treated with Ba-ME $(150 \mu \mathrm{g} / \mathrm{mL})$ for $12 \mathrm{~h}$. Western blot analyses, using whole lysates of the RAW264.7 and HEK293T cells, were performed using antibodies specific for each target protein. The primary antibodies (1:2500) to total and phosphoforms of c-Jun, c-Fos, JNK, p38, ERK, TAK1, and $\beta$-actin, and the secondary antibodies (1:3000) recognizing corresponding isotypes, were used, as reported previously $[33,34]$. The protein bands were detected with the help of an ECL system (Amersham, Little Chalfont, Buckinghamshire, UK).

\subsection{Cellular Thermal Shift Assays}

HEK293T cells were transfected by plasmids expressing TAK1 domain-deletion genes and treated with Ba-ME $(150 \mu \mathrm{g} / \mathrm{mL}$ ) or DMSO (as a control) for $24 \mathrm{~h}$. After treatment, the cells were isolated and resuspended in PBS. The suspended cells were separated into seven PCR tubes with a volume of $100 \mu \mathrm{L}$ and equal numbers of cells. Each PCR tube was heated for $3 \mathrm{~min}$ at a temperature gradient from $49{ }^{\circ} \mathrm{C}$ to $61^{\circ} \mathrm{C}$ and then cooled to $25^{\circ} \mathrm{C}$ for $3 \mathrm{~min}$. We performed three rounds of freezing and thawing using liquid nitrogen and room-temperature water, as reported previously $[35,36]$. The samples were transferred into Eppendorf tubes and centrifuged at 12,000 rpm for $30 \mathrm{~min}$. Protein samples were examined by Western blot analysis.

\subsection{LPS-Induced Peritonitis Mouse Model}

C57BL $/ 6$ male mice ( $n=5$ per group) were injected intraperitoneally with $1 \mathrm{~mL}$ of $4 \%$ thioglycollate broth for 4 days [37,38]. Ba-ME $(100 \mathrm{mg} / \mathrm{kg})$ suspended in $0.5 \% \mathrm{Na}-$ $\mathrm{CMC}$ was administered orally to the thioglycollate-injected mice daily for 5 days using gavage. Acute peritonitis was induced in the thioglycollate-injected mice by intraperitoneal injection of $1 \mathrm{~mL}$ of LPS (10 mg/kg); peritoneal macrophages derived from the mice were collected and plated in RPMI 1640 medium at 1 day after LPS injection. The total RNA in peritoneal exudates was isolated with TRIzol reagent according to the manufacturer's instructions and measured by an mRNA analysis by Quantitative Reverse Transcription Polymerase Chain Reaction.

\subsection{Nitric Oxide (NO) Assay}

Peritoneal macrophages were pre-treated with Ba-ME and then stimulated with LPS. The supernatant $(100 \mu \mathrm{L})$ obtained was mixed with $100 \mu \mathrm{L}$ of Griess reagent. The absorbance of this mixture was measured at $540 \mathrm{~nm}$ and a standard curve was employed to calculate the concentration of NO.

\subsection{Isolation of Peritoneal Macrophage}

After 5 days of oral administration to the thioglycollate-injected mice, we obtained the peritoneal macrophages by IP lavage. The isolated peritoneal macrophages $\left(1 \times 10^{6} \mathrm{cells} / \mathrm{mL}\right)$ were washed with RPMI1640 medium and they were cultured for $4 \mathrm{~h}$ at $37^{\circ} \mathrm{C}$ in $5 \% \mathrm{CO}_{2}$ in a humidified incubator. 


\subsection{Statistical Analysis}

The data are presented as the mean and standard deviation of independent replicate experiments performed in triplicate for statistical comparisons. Statistical comparisons were examined by a Student's $t$-test and a one-way analysis of variance. A $p$-value $<0.05$ was considered statistically significant. All statistical analyses were performed using SPSS software.

\section{Conclusions}

Through the above experiments, we proved that Ba-ME has an anti-inflammatory effect both in vitro and in vivo. Ba-ME effectively suppressed the expression of COX-2 and CCL12 in LPS-stimulated macrophages in a dose-dependent manner. Ba-ME inhibits the activation of AP-1 signaling, as shown by luciferase assay. Further analysis of kinase activities by in vitro assays and Western blotting confirmed that Ba-ME blocks the AP-1 pathway through the expression level of JNK. Employing an overexpression strategy, a CETSA showed that Ba-ME targeted TAK1 to inhibit macrophage-mediated inflammatory responses. In Figure 6, we summarize the inhibitory progression of the AP-1 pathway mechanism of Ba-ME to achieve the anti-inflammatory effects in vitro and in vivo. Our research suggests that Ba-ME could be a potential anti-inflammatory therapeutic.

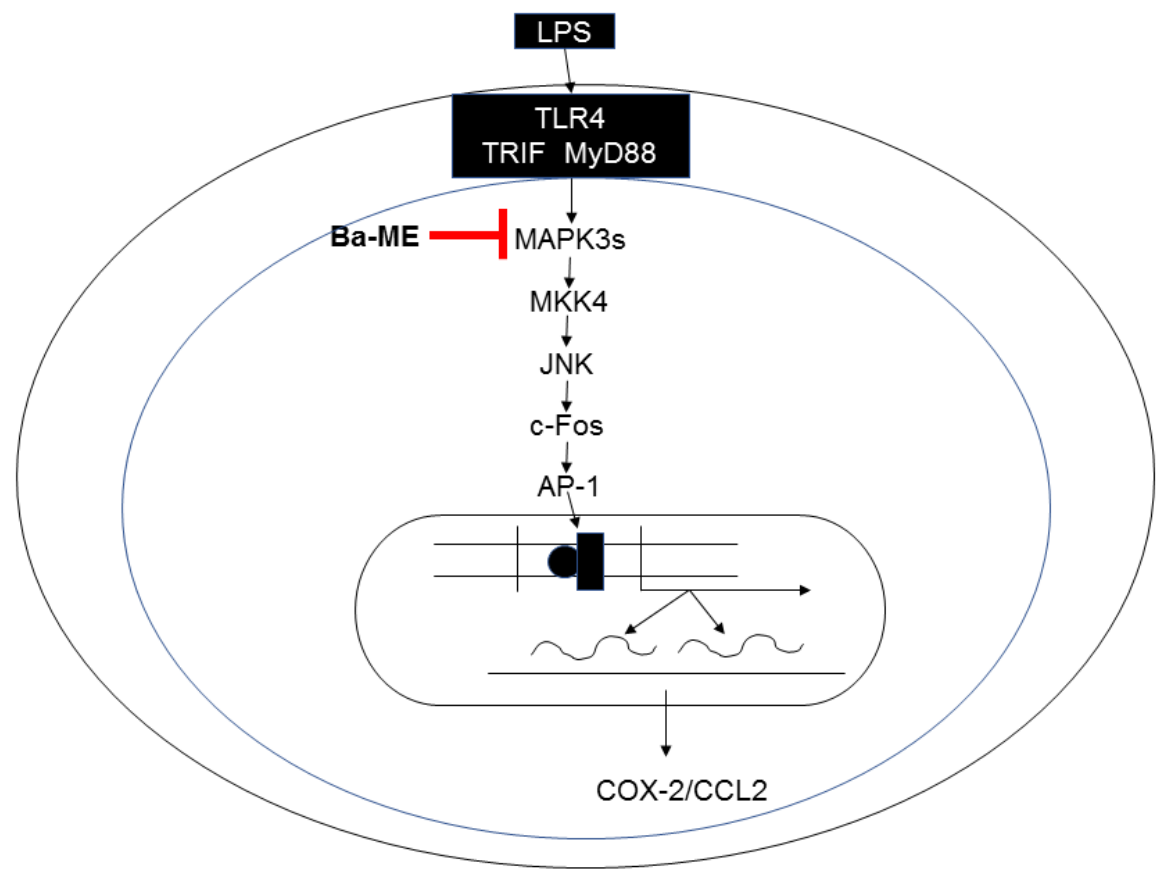

Figure 6. Signaling pathway scheme of Ba-ME's anti-inflammatory action.

Supplementary Materials: The following are available online, Figure S1: HPLC profile of Ba-ME and standard flavonoid compounds (silibinin, genistein, and apigenin).

Author Contributions: A.T.H. conceived and designed the experiments, performed the experiments, analyzed the data, and wrote the paper. M.-Y.K. and J.Y.C. conceived and designed the experiments, analyzed the data, and wrote the paper. All authors have read and agreed to the published version of the manuscript.

Funding: This research was supported by the Basic Science Research Program (2017R1A6A1A03015642) through the National Research Foundation of Korea (NRF) funded by the Ministry of Education, Korea.

Institutional Review Board Statement: Not applicable.

Informed Consent Statement: Not applicable. 
Data Availability Statement: The data used to support the findings of this study are available from the corresponding author upon request.

Acknowledgments: We acknowledge the Foreign Plant Extract Bank of the International Biological Material Research Center (Daejeon, Korea) for allowing us to buy the Ba-ME. We also appreciate Tran The Bach, Sang Mi Eum, Jong Sub Lee, and Eui Su Choung for providing their valuable technical support.

Conflicts of Interest: The authors have no conflicts of interest to declare.

Sample Availability: Sample of Ba-ME is available from the authors.

\section{References}

1. Ferrero-Miliani, L.; Nielsen, O.H.; Andersen, P.S.; Girardin, S.E. Chronic inflammation: Importance of NOD2 and NALP3 in interleukin-1beta generation. Clin. Exp. Immunol. 2007, 147, 227-235. [CrossRef] [PubMed]

2. Xue, Q.; He, N.; Wang, Z.; Fu, X.; Aung, L.H.H.; Liu, Y.; Li, M.; Cho, J.Y.; Yang, Y.; Yu, T. Functional roles and mechanisms of ginsenosides from Panax ginseng in atherosclerosis. J. Ginseng Res. 2021, 45, 22-31. [CrossRef] [PubMed]

3. Kim, J.H.; Yi, Y.S.; Kim, M.Y.; Cho, J.Y. Role of ginsenosides, the main active components of Panax ginseng, in inflammatory responses and diseases. J. Ginseng Res. 2017, 41, 435-443. [CrossRef] [PubMed]

4. Lee, M.S. Role of innate immunity in diabetes and metabolism: Recent progress in the study of inflammasomes. Immune Netw. 2011, 11, 95-99. [CrossRef]

5. Ham, M.; Moon, A. Inflammatory and microenvironmental factors involved in breast cancer progression. Arch. Pharm. Res. 2013, 36, 1419-1431. [CrossRef]

6. Janeway, C.A., Jr. Approaching the asymptote? Evolution and revolution in immunology. Cold Spring Harb. Symp. Quant. Biol. 1989, 54 Pt 1, 1-13. [CrossRef]

7. Tseng, C.K.; Lin, C.K.; Chang, H.W.; Wu, Y.H.; Yen, F.L.; Chang, F.R.; Chen, W.C.; Yeh, C.C.; Lee, J.C. Aqueous extract of Gracilaria tenuistipitata suppresses LPS-induced NF-kappaB and MAPK activation in RAW 264.7 and rat peritoneal macrophages and exerts hepatoprotective effects on carbon tetrachloride-treated rat. PLoS ONE 2014, 9, e86557. [CrossRef]

8. Ciesielska, A.; Matyjek, M.; Kwiatkowska, K. TLR4 and CD14 trafficking and its influence on LPS-induced pro-inflammatory signaling. Cell. Mol. Life Sci. 2021, 78, 1233-1261. [CrossRef]

9. Park, J.G.; Aziz, N.; Cho, J.Y. MKK7, the essential regulator of JNK signaling involved in cancer cell survival: A newly emerging anticancer therapeutic target. Ther. Adv. Med. Oncol. 2019, 11, 1758835919875574. [CrossRef]

10. Gu, Z.; Chen, X.; Yang, W.; Qi, Y.; Yu, H.; Wang, X.; Gong, Y.; Chen, Q.; Zhong, B.; Dai, L.; et al. The SUMOylation of TAB2 mediated by TRIM60 inhibits MAPK/NF-kappaB activation and the innate immune response. Cell Mol. Immunol. 2020. [CrossRef]

11. Yang, W.S.; Kim, H.G.; Lee, Y.; Yoon, K.; Kim, S.; Kim, J.H.; Cho, J.Y. Isoprenylcysteine carboxyl methyltransferase inhibitors exerts anti-inflammatory activity. Biochem. Pharmacol. 2020, 182, 114219. [CrossRef]

12. Yu, T.; Li, Y.J.; Bian, A.H.; Zuo, H.B.; Zhu, T.W.; Ji, S.X.; Kong, F.; Yin, D.Q.; Wang, C.B.; Wang, Z.F.; et al. The regulatory role of activating transcription factor 2 in inflammation. Mediators Inflamm. 2014, 2014, 950472. [CrossRef]

13. Yi, Y.S.; Cho, J.Y.; Kim, D. Cerbera manghas methanol extract exerts anti-inflammatory activity by targeting c-Jun N-terminal kinase in the AP-1 pathway. J. Ethnopharmacol. 2016, 193, 387-396. [CrossRef]

14. Chan, E.D.; Riches, D.W. IFN-gamma + LPS induction of iNOS is modulated by ERK, JNK/SAPK, and p38(mapk) in a mouse macrophage cell line. Am. J. Physiol. Cell Physiol. 2001, 280, C441-C450. [CrossRef]

15. Calixto, J.B.; Campos, M.M.; Otuki, M.F.; Santos, A.R. Anti-inflammatory compounds of plant origin. Part II. modulation of pro-inflammatory cytokines, chemokines and adhesion molecules. Planta Med. 2004, 70, 93-103. [CrossRef]

16. Farlik, M.; Reutterer, B.; Schindler, C.; Greten, F.; Vogl, C.; Muller, M.; Decker, T. Nonconventional initiation complex assembly by STAT and NF-kappaB transcription factors regulates nitric oxide synthase expression. Immunity 2010, 33, 25-34. [CrossRef]

17. Lan, Y.Z.; Bai, Y.L.; Zhu, X.D. Integrated traditional Chinese and Western medicine for ulcerative colitis with diabetes: A protocol for systematic review and meta-analysis. Medicine 2021, 100, e24444. [CrossRef]

18. Sytar, O.; Brestic, M.; Hajihashemi, S.; Skalicky, M.; Kubes, J.; Lamilla-Tamayo, L.; Ibrahimova, U.; Ibadullayeva, S.; Landi, M. COVID-19 prophylaxis efforts based on natural antiviral plant extracts and their compounds. Molecules 2021, 26, 727. [CrossRef]

19. Kindl, M.; Blazekovic, B.; Bucar, F.; Vladimir-Knezevic, S. Antioxidant and anticholinesterase potential of six Thymus species. Evid. Based Complement. Alternat. Med. 2015, 2015, 403950. [CrossRef]

20. Allegra, M. Antioxidant and anti-inflammatory properties of plants extract. Antioxidants 2019, 8, 549. [CrossRef]

21. Amran, N.; Rani, A.N.; Mahmud, R.; Yin, K.B. Antioxidant and cytotoxic effect of Barringtonia racemosa and Hibiscus sabdariffa fruit extracts in MCF-7 human breast cancer cell line. Pharmacogn. Res. 2016, 8, 66-70. [CrossRef] [PubMed]

22. Leamklang, W. Antioxidant Activities of Bioactive Compounds from Barrington Augusta Kurz. and Syzygium gratum (Wight) s.n. Mitra var. Gratum in Ban Anged Official Community Forest Project (the Chaipattana Foundation). Ph.D. Thesis, Biological Science. Burapha University, Chon Buri, Thailand, 2018.

23. Gerlier, D.; Thomasset, N. Use of MTT colorimetric assay to measure cell activation. J. Immunol. Methods 1986, 94, 57-63. [CrossRef] 
24. Kim, E.; Jang, J.; Park, J.G.; Kim, K.H.; Yoon, K.; Yoo, B.C.; Cho, J.Y. Protein arginine methyltransferase 1 (PRMT1) selective inhibitor, TC-E 5003, has anti-inflammatory properties in TLR4 signaling. Int. J. Mol. Sci. 2020, 21, 3058. [CrossRef] [PubMed]

25. Kim, E.; Kang, Y.G.; Kim, J.H.; Kim, Y.J.; Lee, T.R.; Lee, J.; Kim, D.; Cho, J.Y. The atioxidant and anti-inflammatory activities of 8-hydroxydaidzein (8-HD) in activated macrophage-like RAW264.7 cells. Int. J. Mol. Sci. 2018, 19, 1828. [CrossRef]

26. O'Neill, L.A.; Fitzgerald, K.A.; Bowie, A.G. The Toll-IL-1 receptor adaptor family grows to five members. Trends Immunol. 2003, 24, 286-290. [CrossRef]

27. Yang, W.S.; Kim, J.H.; Jeong, D.; Hong, Y.H.; Park, S.H.; Yang, Y.; Jang, Y.J.; Kim, J.H.; Cho, J.Y. 3-Deazaadenosine, an Sadenosylhomocysteine hydrolase inhibitor, attenuates lipopolysaccharide-induced inflammatory responses via inhibition of AP-1 and NF-kappaB signaling. Biochem. Pharmacol. 2020, 182, 114264. [CrossRef]

28. Yang, W.S.; Kim, H.G.; Kim, E.; Han, S.Y.; Aziz, N.; Yi, Y.S.; Kim, S.; Lee, Y.; Yoo, B.C.; Han, J.W.; et al. Isoprenylcysteine carboxyl methyltransferase and its substrate Ras are critical players regulating TLR-mediated inflammatory responses. Cells 2020, 9, 1216. [CrossRef]

29. Lorz, L.R.; Kim, M.Y.; Cho, J.Y. Medicinal potential of Panax ginseng and its ginsenosides in atopic dermatitis treatment. J. Ginseng Res. 2020, 44, 8-13. [CrossRef]

30. Lee, J.O.; Kim, J.H.; Kim, S.; Kim, M.Y.; Hong, Y.H.; Kim, H.G.; Cho, J.Y. Gastroprotective effects of the nonsaponin fraction of Korean Red Ginseng through cyclooxygenase-1 upregulation. J. Ginseng Res. 2020, 44, 655-663. [CrossRef]

31. Rho, T.; Jeong, H.W.; Hong, Y.D.; Yoon, K.; Cho, J.Y.; Yoon, K.D. Identification of a novel triterpene saponin from Panax ginseng seeds, pseudoginsenoside RT8, and its antiinflammatory activity. J. Ginseng Res. 2020, 44, 145-153. [CrossRef]

32. Yoo, S.; Kim, M.Y.; Cho, J.Y. Syk and Src-targeted anti-inflammatory activity of aripiprazole, an atypical antipsychotic. Biochem. Pharmacol. 2018, 148, 1-12. [CrossRef]

33. Lorz, L.R.; Kim, D.; Kim, M.Y.; Cho, J.Y. Panax ginseng-derived fraction BIOGF1K reduces atopic dermatitis responses via suppression of mitogen-activated protein kinase signaling pathway. J. Ginseng Res. 2020, 44, 453-460. [CrossRef]

34. Lee, J.O.; Choi, E.; Shin, K.K.; Hong, Y.H.; Kim, H.G.; Jeong, D.; Hossain, M.A.; Kim, H.S.; Yi, Y.S.; Kim, D.; et al. Compound K, a ginsenoside metabolite, plays an antiinflammatory role in macrophages by targeting the AKT1-mediated signaling pathway. $J$. Ginseng Res. 2019, 43, 154-160. [CrossRef]

35. Shaw, J.L.; Leveridge, M.; Norling, C.; Karén, J.; Molina, D.M.; O’Neill, D.; Dowling, J.E.; Davey, P.; Cowan, S.; Dabrowski, M.; et al. Determining direct binders of the adrogen rceptor using a high-throughput cllular termal sift asay. Sci. Rep. 2018, 8, 163. [CrossRef]

36. Choi, E.; Kim, M.Y.; Cho, J.Y. Anti-inflammatory activities of Canarium subulatum Guillaumin methanol extract operate by targeting Src and Syk in the NF-kappaB pathway. J. Ethnopharmacol. 2019, 238, 111848. [CrossRef]

37. Ma, T.W.; Wang, Z.; Zhang, Y.-M.; Luo, J.-G.; Kong, L.-Y. Bioassay-guided isolation of anti-inflammatory components from the bulbs of Lilium brownii var. viridulum and identifying the underlying mechanism through acting on the NF- $\mathrm{KB} / \mathrm{MAPKs}$ pathway. Molecules 2017, 22, 506. [CrossRef]

38. Hong, Y.H.; Kim, J.H.; Cho, J.Y. Ranunculus bulumei methanol extract exerts anti-inflammatory activity by targeting Src/Syk in NF-kappaB signaling. Biomolecules 2020, 10, 546. [CrossRef] 